\title{
CORRESPONDENCE.
}

\section{ON THE VALUE OF A POLICY ON THE LONGEST OF TWO LIVES.}

\section{To the Editor of the Journal of the Institute of Actuaries.}

Srr,-It has been demonstrated in the Journal, vol. xi., page 104, that the Value of the Policies existing in an Office is equal to the accumulated net Preminms less the claims. The application of this result to an ordinary Poliey on a single life is shown in the formula $\frac{\mathbf{N}_{x-1}-\mathbf{N}_{x+n-1}}{\mathbf{D}_{x+n}} \cdot \frac{\mathbf{M}_{x}}{\mathbf{N}_{x-1}}-\frac{\mathbf{M}_{x}-\mathbf{M}_{x+n}}{\mathbf{D}_{x+n}}$, vol. xi., page 107, where $\frac{\mathbf{M}_{x}}{\mathbf{N}_{x-1}}=\varpi_{x}$. This formula will also apply, by simply changing the values of $M, N, D$, and $w$, to Policies of some other descriptions, viz., those where no alteration takes place in their status till their expiry or till claims arise on them, as for instance, Policies on Joint Lives, Endowment Assurances and Term Policies. But the formula will not be applicable, at least by a like simple modification, to the case of Policies, the status of which may be changed during their continnance, as that of Policies on the Longest of two lives, which may be changed by the dropping of one life.

I have thonght a similar demonstration in the case of a Policy on the Longest of two lives to the one above referred to might not be without interest.

Let there be $l_{x}$ lives of the age $x$ and $l_{y}$ of the age $y$, then the number of pairs which can be formed ont of them, each containing a life aged $x$ and a life aged $y$, is $l_{x} \times l_{y *}$. Let this be expressed by $l_{x y}$, so that in the following demonstration $l_{x, y}$ signifies $l_{x} \times l_{y}$. Let each of these $l_{x, y}$ pairs be assured for $\mathfrak{E l}$ payable on the last death, at an annual net Preminm $\approx$. Then the number of claims (that is, of pairs in which both lives become extinct) in the first year, will be $l_{x x y}-l_{x y+1}-l_{x+1}+l_{x+1, y+1}$; and the sum reserved at the end of the first year for existing Policies will be

$$
l_{x . y} \varpi(1+i)-\left(l_{x, y}-l_{x, y+1}-l_{x+1, y}+l_{x+1, y+1}\right)
$$

But of the latter Policies there will be $l_{x+1 . y}-l_{x+1 . y+1}$, by which only sur- 
viving single lives aged $x+1$ are assured, and $l_{x . y+1}-l_{x+1 . y+1}$, by which only single lives aged $y+1$ are assured. The value of these Policies will be

$$
\begin{array}{r}
\left(l_{x+1 . y}-l_{x+1 y+1}\right)\left\{1-(d+\varpi)\left(1+a_{x+1}\right)\right\} \\
+\left(l_{x y+1}-l_{x+1 . y+1}\right)\left\{1-(d+\varpi)\left(1+a_{y+1}\right)\right\}
\end{array}
$$

which dedueted from (1) will give the value of the Policies on the $l_{x+1} y+1$ surviving pairs of lives.

The investigation of this for the first year is as follows:

In $\left(l_{x+1 . y}-l_{x+1 . y+1}\right)\left\{1-(d+\varpi)\left(1+a_{x+1}\right)\right\}$

$$
\begin{gathered}
l_{x+1 . y}\left(1+a_{x+1}\right)=l_{x . y} \cdot \frac{l_{x+1}}{l_{x}}\left(1+a_{x+1}\right)=(1+i) l_{x . y} a_{x} \\
\therefore \quad-l_{x+1 . y}\left\{1-(d+\infty)\left(1+a_{x+1}\right)\right\}=-l_{x+1 . y}+(1+i) l_{x . y}(d+\varpi) a_{x} \\
\text { and } \quad-l_{x . y+1}\left\{1-(d+\varpi)\left(1+a_{y+1}\right)\right\}=-l_{x . y+1}+(1+i) l_{x, y}(d+\varpi) a_{y}
\end{gathered}
$$

The snm of these is

$$
-l_{x+1 . y}-l_{x . y+1}+(1+i) l_{x \cdot y}(d+\pi)\left(a_{x}+a_{y}\right)
$$

and the other terms of (2), with their signs changed, are equal to

$$
l_{x+1 \cdot y+1}\left(\mathrm{~A}_{x+1}+\mathrm{A}_{y+1}\right)-l_{x+1 . y+1}\left(2+a_{x+1}+a_{y+1}\right) w .
$$

Again, $\quad \mathbf{A}_{x+1 . y+1} l_{x+1 . y+1}=\mathbf{A}_{x \cdot y} l_{x \cdot y}(1+i)-\left(l_{x \cdot y}-l_{x+1 . y+1}\right)$

and

$$
\left(a_{x+1, y+1}+1\right) l_{x+1, y+1}=a_{x, y} l_{x x y}(1+i)
$$

If all the terms of (1), and (2) as above modified, are collected and $A_{x+1 . y+1} l_{x+1, y+1}$ and $\left(a_{x+1, y+1}+1\right) l_{x+1 . y+1}$ are added and subtracted according to equations $(a)$ and $(b)$, the result is

$$
\begin{aligned}
& -l_{x y}+l_{x+1 . y}+l_{x, y+1}-l_{x+1, y+1}-l_{x+1 . y}-l_{x, y+1} \\
& +(1+i) l_{x . y} d\left(a_{x}+a_{y}\right)+(1+i) l_{x, y} \mathbf{A}_{x . y}-l_{x . y}+l_{x+1, y+1} \\
& +(1+i) l_{x: y} \sigma+(1+i) l_{x, y}\left(a_{x}+a_{y}\right) \sigma-(1+i) l_{x, y} a_{x \cdot y \cdot w^{*}} \\
& +l_{x+1 . y+1}\left(\mathrm{~A}_{x+1}+\mathrm{A}_{y+1}-\mathrm{A}_{x+1 . y+1}\right)-l_{x+1 . y+1}\left(1+a_{x+1}+a_{y+1}-a_{x+1 . y+1}\right) \varpi \text {. } \\
& \text { Now } l_{x \cdot y}=(1+i) v l_{x: y} \text { and } \mathrm{A}_{x}=v-(1-v) a_{x}=v-d a_{x} \\
& \therefore-2 l_{x \cdot y}+(1+i) l_{x \cdot y} d\left(a_{x}+a_{y}\right)+(1+i) l_{x \cdot y} A_{x . y} \\
& =-(1+i) l_{x, y}\left\{2 v-d\left(a_{x}+a_{y}\right)-\mathbf{A}_{x, y}\right\} \\
& =-(1+i) l_{x y y}\left(\mathrm{~A}_{x}+\mathrm{A}_{y}-\mathrm{A}_{x \cdot y}\right) \\
& \varpi=\frac{\mathbf{A}_{x}+\mathbf{A}_{y}-\mathbf{A}_{x y}}{1+a_{x}+a_{y}-a_{x y}} \\
& \therefore \quad(1+i) l_{x . y}\left(1+a_{x}+a_{y}-a_{x y}\right) \text { w }=(1+i) l_{x . y}\left(\mathbf{A}_{x}+\mathbf{A}_{y}-\mathbf{A}_{x y y}\right)
\end{aligned}
$$

Therefore the sum of the terms in the above result before the asterisk (*) vanishes, and the remaining terms divided by $l_{x+1 . y+1}$ are equal to

$$
\mathrm{A}_{x+1}+\mathrm{A}_{y+1}-\mathrm{A}_{x+1 \cdot y+1}-\left(1+a_{x+1}+a_{y+1}-a_{x+1} y+1\right) w_{,}
$$

the formula for the value of a Policy on the longest of two lives.

I am, $\mathrm{Sir}$,

7, Royal Exchange,

Your obedient servant,

June, 1868.

THOS. CARR. 